\title{
Perancangan Sistem Informasi Manajemen Ekstrakurikuler Berbasis Web Pada Sekolah Menengah Kejuruan Negeri 5 Kota Bandung
}

\author{
Herdian Nuryansyah ${ }^{[1] *}$, Egy Hermawan ${ }^{[2]}$ \\ Program Studi Sistem Informasi ${ }^{[1], ~[2] ~}$ \\ Politeknik Piksi Ganesha ${ }^{[1],[2]}$ \\ Bandung, Indonesia \\ e-mail: hnuryansyah@piksi.ac.id ${ }^{[1]}$, ehermawan@piksi.ac.id ${ }^{[2]}$
}

\begin{abstract}
Extracurriculars in education are meant to address the needs of learners. By taking extracurriculars, students will be helped by a creative learning pattern that increases creativity. In fact, in limited school hours, many activities are not always possible, creating extracurriculars which carried out outside school hours to accommodate learners who meet their interests and talents. Operation of an extra-curricular information system on SMK Negeri 5 Bandung has a problem, in which students sometimes do not get information such as schedules, values, extracurricular activities and extracurricular registration are done by collecting applications that this activity leads to a buildup of files that are most ineffectual today. From the problems that researchers create an extrapolate-management information system with HTML programming languages, PHP, bootstrap, MySQL and databases. The system was tested using usability testing methods that are directly tested for extracurricular members. The method used in the construction of the system was the waterfall method. The results of testing the web-based Extracurricular Management Information System on the usability testing aspect got $\mathbf{7 9 . 5 5 \%}$ results, meaning that they were able to solve the problem of unstructured information to extracurricular members at SMK Negeri 5 Bandung. So that it can be said, the Web-based Extracurricular Management Information System has met the usability testing aspect and is feasible to use.
\end{abstract}

Keywords- Information system, management, web based, extracurricular.

Abstrak - Ekstrakurikuler dalam pendidikan dimaksud untuk menjawab tuntutan kebutuhan peserta didik. Dengan mengikuti ekstrakurikuler, maka siswa akan dibantu dengan pola belajar yang kreatif mampu meningkatkan kreativitas. Kenyataannya dalam jam-jam sekolah yang terbatas banyak kegiatan yang tidak selalu dapat dilakukan, maka terciptalah ekstrakurikuler yang dimana pelaksanaannya dilakukan diluar jam sekolah untuk menampung peserta didik dalam memenuhi kebutuhan minat dan bakat mereka. Pengelolaan sistem informasi ekstrakurikuler pada SMK Negeri 5 Bandung memiliki kendala, dimana siswa terkadang tidak mendapatkan informasi seperti jadwal, nilai, kegiatan esktrakurikuler dan pendaftaran ekstrakurikuler dilakukan dengan cara mengumpulkan formulir pendaftaran yang dimana kegiatan ini mengakibatkan penumpukan berkas yang tentunya sangat tidak efektif di zaman sekarang. Dari permasalahan yang ada maka peneliti membuat sistem informasi manajemen ekstrakurikuker berbasis web dengan bahasa pemrograman HTML, PHP, Bootstrap, MySQL dan database. Sistem ini diuji menggunakan metode pengujian usability testing yang langsung diujikan kepada anggota ekstrakurikuler. Metode yang digunakan dalam pembangunan sistem tersebut adalah metode waterfall. Hasil testing Sistem Informasi Manajemen Ekstrakurikuler berbasis web pada aspek usability testing mendapatkan hasil $\mathbf{7 9 , 5 5 \%}$ yang artinya sudah mampu menyelesaikan masalah tidak terstukturnya informasi kepada anggota ekstrakurikuler yang ada di SMK Negeri 5 Bandung. Sehingga dapat disimpulkan, Sistem Informasi Manajemen Ekstrakurikuler berbasis Web sudah memenuhi aspek usability testing dan layak digunakan.

Kata Kunci-Manajemen, sistem informasi, berbasis web, ekstrakurikuler.

\section{PENDAHULUAN}

Pendidikan adalah suatu media untuk memajukan seluruh aspek dalam bidang kehidupan manusia, seperti aspek technology, ekonomi, keselamatan, sosial, keterampilan, ketentraman, kemajuan bangsa dan budaya [1]. Pencapaian hasil yang maksimal dalam pendidikan harus dilakukan pengembangan dan perbaikan secara terus menerus. Secara akademik siswa diberikan pembelajaran mengenai ilmu yang bersifat ilmiah, pengetahuan dan teori. Dalam meningkatkan keterampilan siwa maka diberikan pembelajaran dari segi nonakademik untuk meningkatkan keterampilan sesuai dengan bakat dan minatnya masing-masing Untuk menggapai hasil pendidikan yang terbaik, pembelajaran tidak cukup dari pendidikan formal sajah, tapi perlu juga pendidikan nonformal seperti esktrakurikuler[2].

Kegiatan ekstrakurikuler adalah kegiatan diluar program yang tertulis didalam kurikulum pembelajaran. Kegiatan ekstrakurikuler ditujukan kepada siswa untuk mengembangkan bakat dan kemampuannya dibidang lain diluar bidang akademik [3]. Dengan mengikuti ekstrakurikuler maka siswa akan dibantu dengan pola belajar yang kreatif mampu meningkatkan kreativitas. Kenyataannya dalam jam-jam sekolah yang terbatas banyak kegiatan yang tidak selalu dapat dilakukan, maka terciptalah ekstrakurikuler yang dimana pelaksanaannya 
dilakukan diluar jam sekolah untuk menampung peserta didik dalam memenuhi kebutuhan minat dan bakat mereka.

Indonesia telah menerapkan teknologi dalam bidang pendidikan seperti pendaftaran online, sistem ujian online dan masih banyak lainnya yang mendukung kemajuan dan pelaksaan pendidikan di Indonesia. Untuk mengontrol manajemen kegiatan sekolah, sekarang banyak sekolah yang mempunyai sistem informasi untuk membantu pihak sekolah dalam mengelola manajemen kegiatan sekolah, tapi tidak semua sekolah mempunyai sistem informasi kegiatan untuk mengelola ekstrakurikuler. Pengelolaan sistem informasi ekstarakurikuler pada SMK Negeri 5 Bandung memiliki kendala.

Berdasarkan hasil wawancara dengan beberapa pembimbing ekstrakurikuler mengatakan bahwa kegiatan ekstrakurikuler seperti: (1) berita kegiatan, pelaksanaan kegiatan, informasi berupa pengumuman dari pihak sekolah maupun oleh pembina masih sangat kurang sehingga para anggota ekstrakurikuler kurang mendapatkan informasi, (2) terdapat permasalahan dalam pencarian data dan pengubahan data anggota/alumni ekskul, (3) SMK Negeri 5 Bandung belum mempunyai sistem informasi untuk kegiatan ekstrakurikuler sehingga mengurangi batasan penerima informasi.

Tujuan penelitian ini untuk menyelesaikan permasalahan tidak terstrukturnya informasi yang ada di ekstrakurikuler SMK Negeri 5 Bandung, peneliti menyampaikan jalan keluar yaitu membangun suatu sistem informasi manajemen ekstrakurikuler berbasis web, dengan bahasa pemrograman HTML, PHP, Bootstrap, MySQL dan database yang bermanfaat untuk mengontrol manajemen informasi kegiatan ekstrakurikuler di SMK Negeri 5 Bandung. Sistem ini diharapkan dapat mempermudah proses manajemen informasi ekstrakurikuler dan dapat memberikan informasi secara luas mengenai kegiatan ekstrakurikuler itu sendiri, agar penginformasi yang diberikan tidak terurai dan terintegrasi dalam satu sistem dan dapat berguna bagi siswa, guru, sekolah dan orang tua.

Dalam pembuatan system diperlukan adanya batasan masalah agar terhindari dari pembuatan system yang tidak terstruktur dan mampu mempercepat proses pembuatan system ini sendiri. System ini akan terfokus pada informasi tentang list ekstrakurikuler, berita kegiatan, gallery kegiatan, jadwal kegiatan, nilai anggota ekstrakurikuler, dan informasi alumni setiap ekstrakurikuler.

\section{LANDASAN TEORI}

\section{A. Definisi Perancangan}

Perancangan adalah sebuah aktivitas yang mempunyai maksud untuk mendesain suatu system baru yang bisa mengatasi permasalahan yang menimpa perusahaan, melaui proses yang didapat dari pemilihan system yang terunggul. Perancangan adalah suatu proses penerjemahan hasil dari pengamatan suatu system ke dalam bahasa pemrograman yang bertujuan untuk menguraikan system secara terperinci sebagaimana struktur yang di terapkan [4].

\section{B. Sistem Informasi Manajemen}

Sistem informasi manajemen adalah rentetan system yang tertata dari beberapa komponen untuk memberikan hasil informasi yang dapat dipergunakan disuatu manajemen perusahaan [5]. Tujuan dari sistem informasi manajemen ini adalah untuk mengatur sumber daya yang dimiliki untuk mencapai tujuan organisasi yang telah ditetapkan [5]

Banyak manfaat yang dimiliki oleh Sistem informasi manajemen, diantaranya seperti [6]:

1) Menaikan kemampuan dan keefektifan data secara tepat waktu dan akurat.

2) Mempermudah bagian manajemen untuk melakukan pendelegasian, pemeriksaan, dan pengarahan kerja kepada unit yang mempunyai keterkaitan.

3) Menaikan kualitas keahlian manusia, supaya unit system kerja bisa tersinkronisasi dan terstruktur.

4) Menghemat biaya anggaran dan meningkatkan produktivitas di dalam organisasi.

\section{Ekstrakurikuler}

Aktivitas Ekstrakurikuler merupakan suatu aktivitas yang di selenggarakan di luar atau di dalam area sekolah yang memiliki tujuan untuk mengembangkan kemampuan dan kreativitas siswa melalui latihan sesuai dengan aktivitas yang disukai. Untuk meningkatkan keterampilan siswa maka dibentuklah latihan khusus sesuai dengan ekstrakurikulernya masingmasing untuk mendapatkan hasil yang maksimal [7].

Ekstrakurikuler memiliki manfaat menambah wawasan dalam menerapkan nilai-nilai pengetahuan dan keterampilan dalam beberapa aspek seperti seni dan olahraga. Aktivitas ekstrakurikuler juga menjadi sarana atau wadah untuk mengembangkan dan menampung potensi siswa yang tidak terpenuhi pada saat di sekolah [7].

\section{D. $H T M L$}

HyperText Markup Language merupakan bahasa markup yang di pergunakan untuk membangun halaman web, yang berfungsi untuk menampilkan berbagai macam informasi dari dunia maya atau internet. Untuk mewujudkan tampilan yang terintegrasi maka HTML menggunakan teknik formatting hypertext yang dimana berkas ditulis menggunakan format ASCII [8].

\section{E. $P H P$}

PHP merupakan script pemrograman yang berjalan dan terletak di sebuah server yang memiliki fungsi untuk mengolah, menampilkan, dan menerima data dari sebuah situs. Data akan diolah ke dalam database server untuk hasil akhirnya diperlihatkan di halaman sebuah situs [9].

\section{F. Database}

Database adalah sekumpulan data yang berhubungan secara logis dan memiliki deskripsi dari setiap data, serta dirancang untuk menemukan informasi yang dibutuhkan oleh user. Efisiensi merupakan salah satu hal yang diperhatikan dalam pembuatan database [8]. Dalam mengelola database diperlukan sebuah perangkat lunak yang disebut dengan 
Database Management System. DBMS adalah software yang digunakan untuk memudahkan proses mengubah, menghapus dan memasukan informasi terhadap database [10].

\section{G. $M y S Q L$}

My Structured Query Language adalah suatu system database relasional yang mampu mengklasifikasikan informasi ke dalam tabel yang terhubung. Masing-masing tabel dapat memuat bidang-bidang terpisah, yang memperlihatkan setiap bit informasi. Dengan memanfaatkan indeks MySQL mempercepat proses penelusuran terhadap informasi tertentu [11]. Dengan memanfaatkan indeks MySQL mempercepat proses penelusuran terhadap informasi tertentu. Dalam operasi client server pada mysql melibatkan server daemon yang memiliki berbagai macam program serta library yang berjalan pada client [12].

\section{H. Bootstrap}

Bootstrap merupakan framework CSS Untuk membantu pekerjaan seorang pendesain website atau seorang programmer agar mempercepat proses pembuatan tampilan dari sebuah website, pemakaian bootstrap juga mampu untuk memperindah desain pada system [10]. Dengan memanfaatkan indeks MySQL mempercepat proses penelusuran terhadap informasi tertentu. Dalam operasi client server pada mysql melibatkan server daemon yang memiliki berbagai macam program serta library yang berjalan pada client [12].

\section{I. $U M L$}

Unified Modeling Language merupakan gambar atau grafik untuk memvisualisasikan, pendokumentasian, membangun dan menspesifikasikan suatu system perangkat lunak yang dikembangkan secara Object-Oriented. UML memiliki standar pencatatan sebuah sistem blue-print, terdiri dari gambaran proses suatu pencatatan kelas-kelas kedalam program yang lebih spesifik, database yang terintegrasi, dan komponen lain yang dibutuhkan oleh system [10]. Dengan kata lain, seorang programmer menggunakan diagram UML untuk membantu mengembangkan perangkat lunak [8].

\section{METODE PENELITIAN}

Metodologi penelitian adalah rencana yang akan dilaksanakan dengan cara ilmiah dan sistematis. Dalam penelitian ini ditingkatkan dengan merencanakan penelitian agar mudah dilaksanakan. Untuk mengumpulkan data yang berhubungan dengan laporan penelitian, maka peneliti menggunakan teknik wawancara langsung untuk mengumpulkan data dari pihak SMK Negeri 5 Bandung yang bersangkutan dan melakukan reduksi data atau pengkategorian untuk menyaring data yang sesuai dengan kebutuhan, serta melakukan observasi, studi dokumentasi dan studi pustaka dari pihak sekolah dan internet. Penelitian ini menggunakan metode waterfall untuk mengembangkan sistem informasi yang sistematis dan berurutan [11].

Penelitian ini menggunakan metode waterfall untuk mengembangkan sistem informasi yang sistematis dan berurutan [11]. Menurut Pressman, dengan menggunakan model waterfall dalam membangun software termasuk kedalam model sistematis yang klasik [10]. Metode waterfall terdiri dari 5 tahapan pengembangan yang digambarkan pada gambar 1 .

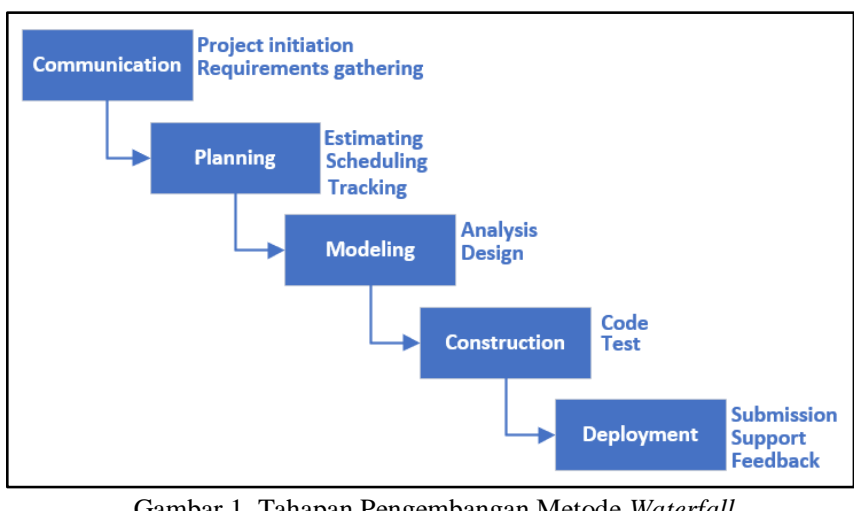

Gambar 1. Tahapan Pengembangan Metode Waterfall

\section{1) Communication}

Communication adalah tahapan pertama yang dilakukan dengan cara berinteraksi dan berkomunikasi oleh peneliti kepada pihak SMK Negeri 5 Bandung yang terkait, seperti Wakil Kepala Sekolah bidang kesiswaan, pembimbing ekstrakurikuler, staff kesiswaan dan siswa tentang sistem informasi manajemen ekstrakurikuler di SMK Negeri 5 Bandung yang selama ini sedang berjalan. Untuk mendukung kebutuhan aplikasi yang akan dibangun, maka dilakukan komunikasi yang menghasilkan inisialisasi project seperti mengumpulkan data yang dibutuhkan dan menganalisa permasalahan [13].

\section{2) Planning}

Planning adalah tahapan kedua untuk menetapkan strategi mengenai sistem yang akan dibuat berdasarkan kebutuhan. Peneliti mengajukan planning untuk membuat sistem informasi manajemen ekstrakurikuler berbasis web serta dapat diakses secara mobile kepada pihak sekolah [13].

\section{3) Modeling}

Modeling adalah tahapan ketiga untuk merancang user interface design yang akan dibuat, dengan memperhatikan kemudahan dan kenyamanan user dalam mengakses website. Tahapan ini memiliki tujuan diantaranya untuk membuat gambaran dan menafsirkan maksud dari aplikasi [13].

\section{4) Construction}

Construction adalah tahapan keempat untuk membuat kode program yang telah dirancang sesuai dengan user interface design. Setelah pembuatan program selesai, dilakukan usability testing pada system bertujuan untuk mendeteksi kesalahan yang mungkin akan terjadi sehingga dapat diperbaiki [13].

\section{5) Deployment}

Deployment adalah tahapan kelima untuk mengimplementasikan aplikasi ke user, evaluasi aplikasi, pengembangan aplikasi dan pemeliharaan aplikasi secara 
berkala berdasarkan feedback yang diberikan supaya system dapat terus berkembang dan berjalan sesuai dengan semestinya [13].

Kerangka kerja penelitian merupakan langkah-langkah dalam aktivitas ilmiah yang diterapkan dalam melakukan penelitian. Pada metode penelitian ini terdapat 6 tahapan yang dilakukan, seperti gambar 2 dibawah ini :

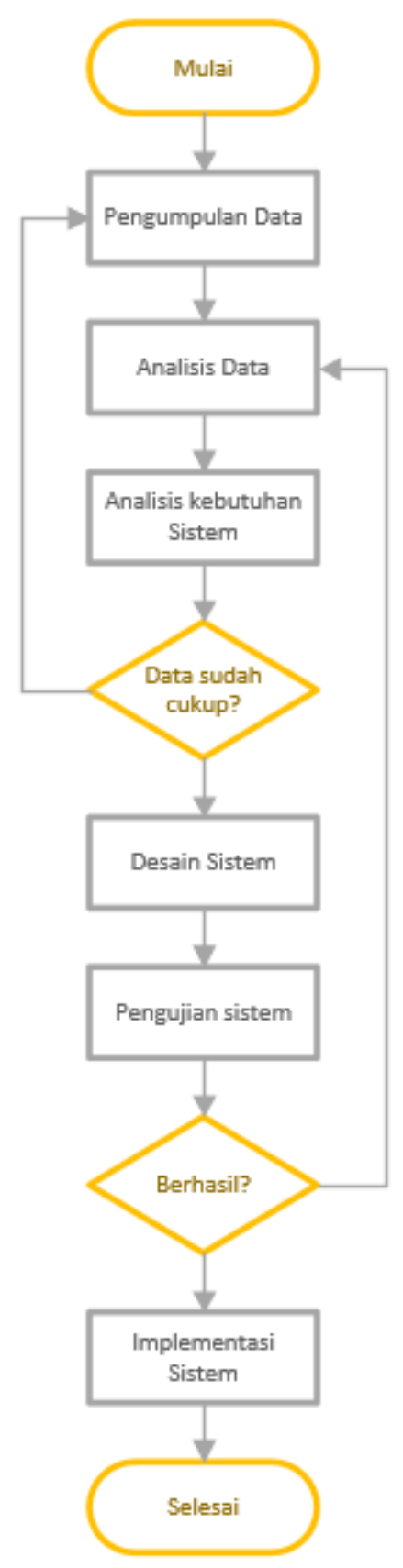

Gambar 2. Flowrchart Penelitian siswa. Analisis dilakukan untuk mengetahui kebutuhan user pada sistem yang dibangun, pengujian dilakukan untuk mengetahui kemampuan sistem dalam mengolah informasi

\section{PEMBAHASAN}

\section{1) Perancangan Aplikasi}

Tahapan ini dirancang untuk membuat aplikasi berdasarkan data yang telah diperoleh dari pengumpulan data serta hasil analisa kebutuhan. Kegiatan memiliki tujuan untuk mendesain system baru yang dapat menyelesaikan permasalahan yang dihadapi oleh pihak SMK Negeri 5 Bandung [6].

\section{a) Activity Diagram}

Activity Diagram menunjukkan system activities dalam bentuk himpunan tindakan, dari bagaimana dimulainya setiap tindakan tersebut yang menghasilkan keputusan yang mungkin terjadi pada akhir tindakan. Dalam waktu yang bersamaan Activity Diagram dapat menggambarkan lebih dari satu aksi [14]. Proses alur kerja sistem informasi untuk memperlihatkan urutan aktivitas yang dikerjakan sebagai berikut:

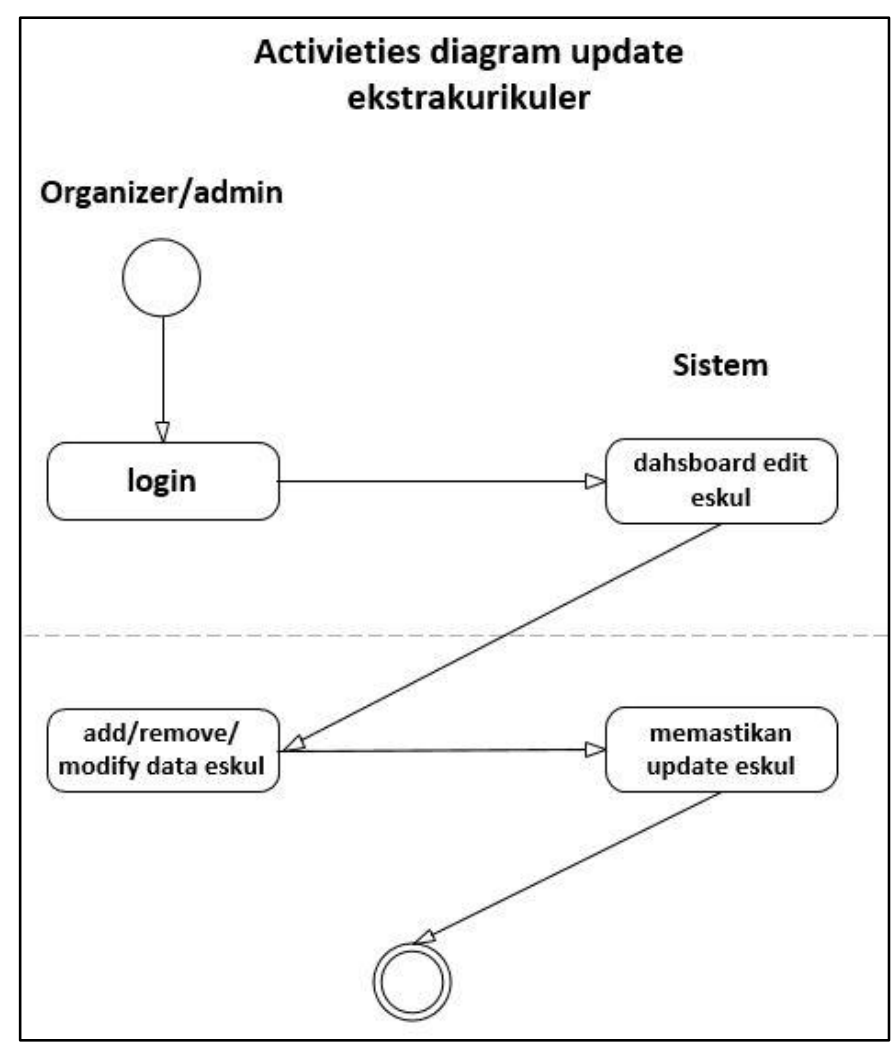

Gambar 3. Activities Diagram Update Ekstrakurikuler

Penelitian ini dimulai dari pengumpulan data dilakukan dengan cara observasi serta wawancara kepada pihak SMK Negeri 5 Bandung, yang meliputi Wakil Kepala Sekolah bidang kesiswaan, pembimbing ekstrakurikuler, staff kesiswaan dan 


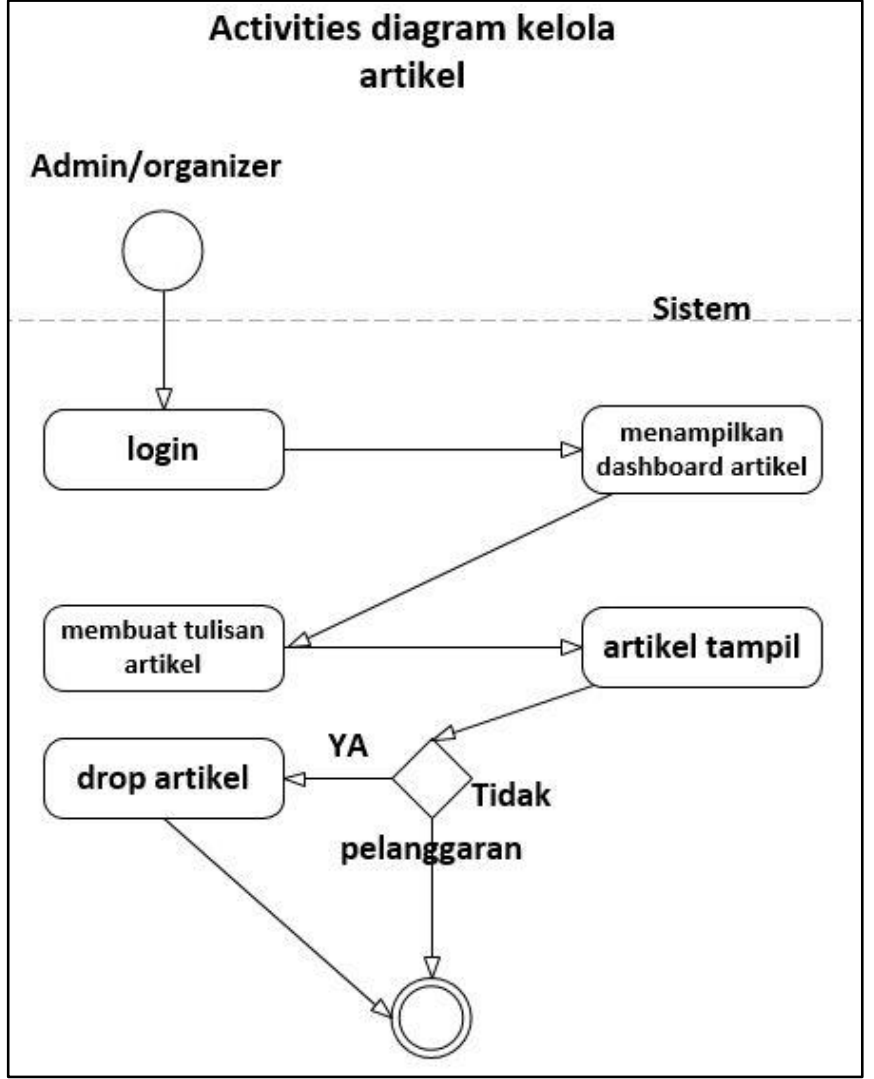

Gambar 4. Activities Diagram Kelola Artikel

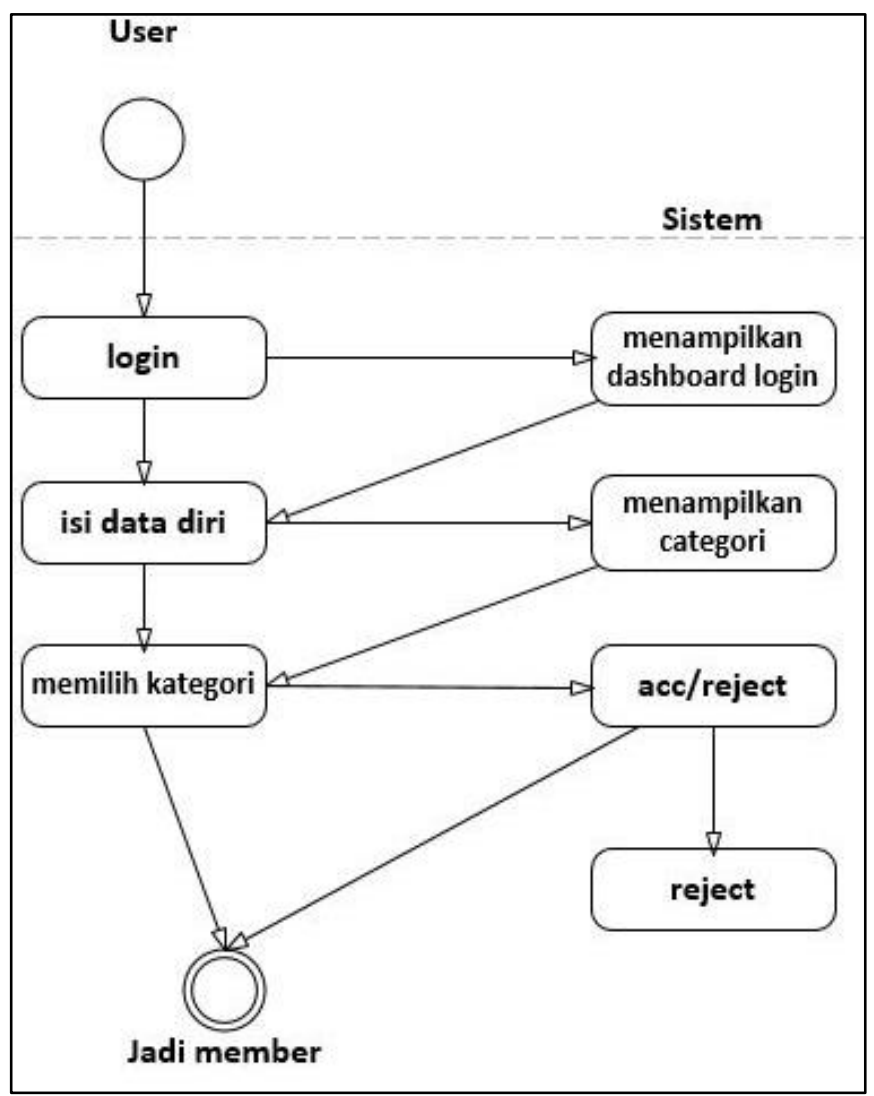

Gambar 5. Activities Diagram Join Member

\section{b) Use Case Diagram}

Use Case Diagram menunjukan perspektif user terhadap kebutuhan system, yang mengilustrasikan keterkaitan antara use case dengan actors dalam system [15]. Use Case memiliki kegunaan untuk mengetahui apa saja fungsi yang ada pada system dan menunjukan siapa yang berwenang memakai fungsi-fungsi tersebut. [16].

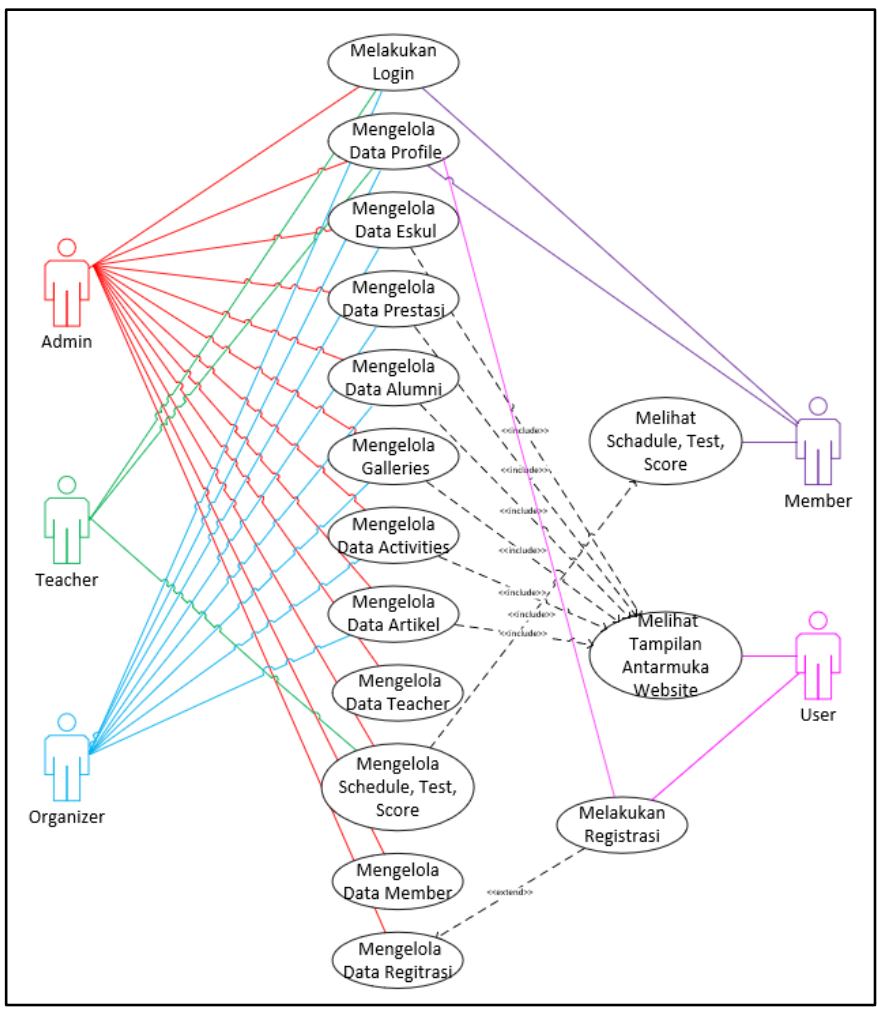

Gambar 6. Use Case Diagram

c) Class Diagram

Class Diagram menunjukan hubungan antar Class dengan penjelasan detail dari setiap Class di dalam model system design, serta menunjukan tanggung jawab entitas dan aturan sesuai dengan tindakan system. Class Diagram juga memperlihatkan operasi dan atribut dari setiap Class dan kendali yang terhubung dengan objek yang saling berkaitan [16]. 


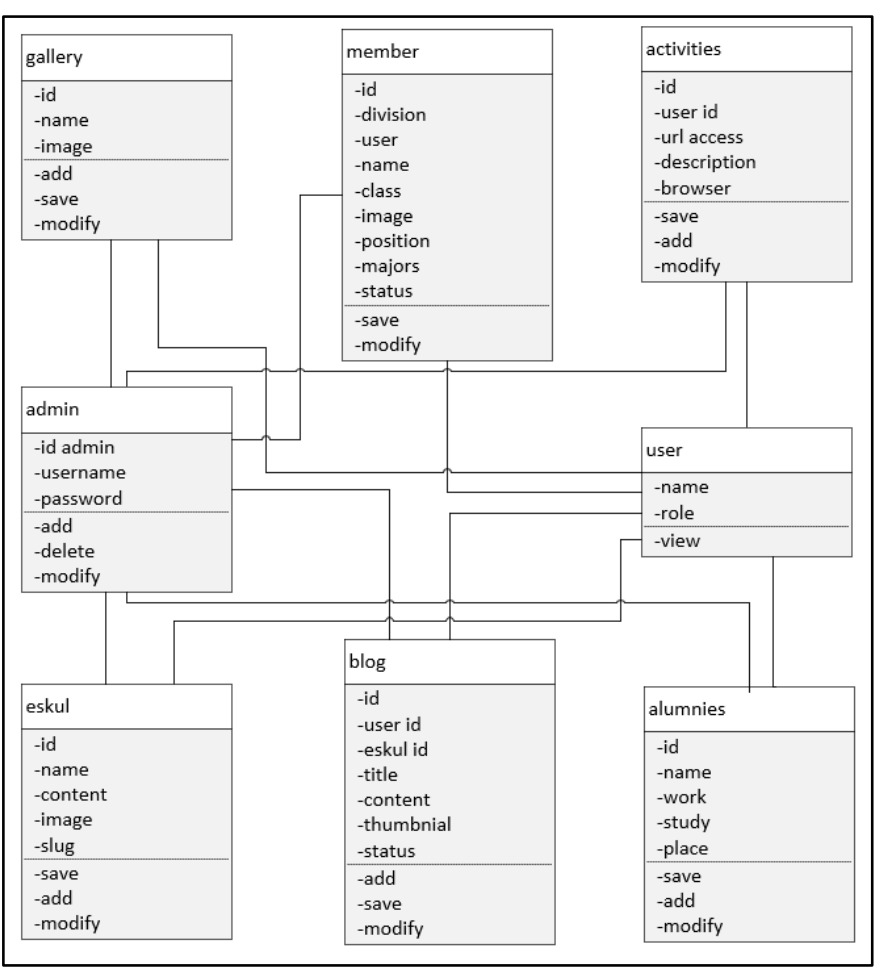

Gambar 7. Class Diagram

\section{2) Implementasi Aplikasi}

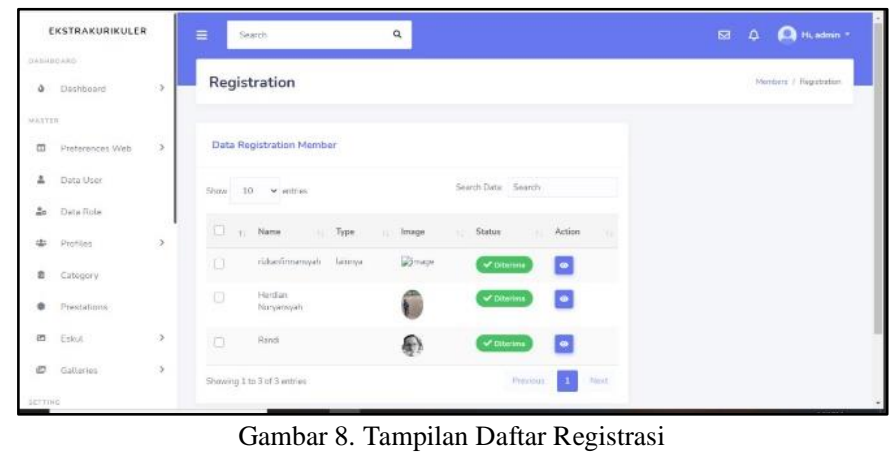

Gambar 8 menunjukan halaman daftar registrasi yang dapat diakses oleh Organizer, Teacher, Member dan User. Pada gambar ini terdapat data seperti name, type, images, status dan action.

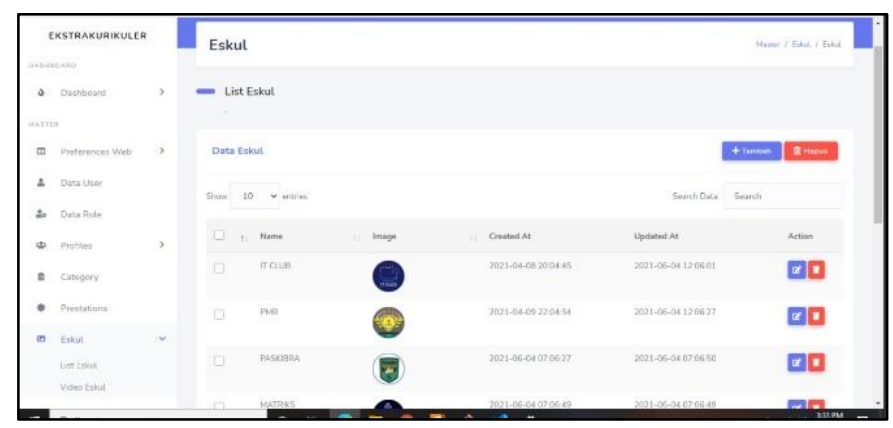

Gambar 9. Tampilan Data Esktrakurikuler
Gambar 9 menunjukan halaman untuk mengelola data ekstrakurikuler, Admin dan Organizer dapat melakukan penambahan, penghapusan dan pengubahan data ekstrakurikuler. Pada gambar ini terdapat data seperti name, images, created at, upload at dan action.

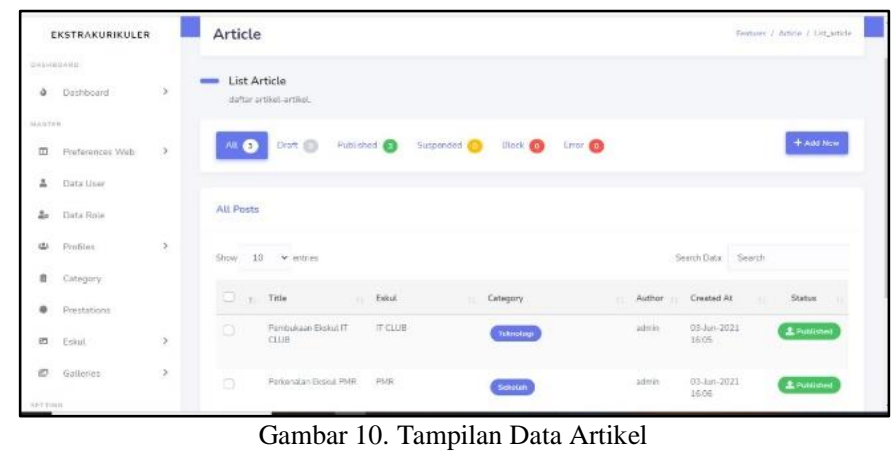

Gambar 10 menunjukan halaman untuk mengelola data artikel, Admin dan Organizer dapat melakukan penambahan, penghapusan dan pengubahan data artikel. Pada gambar ini terdapat data seperti tittle, eskul, category, author, created at dan status. 


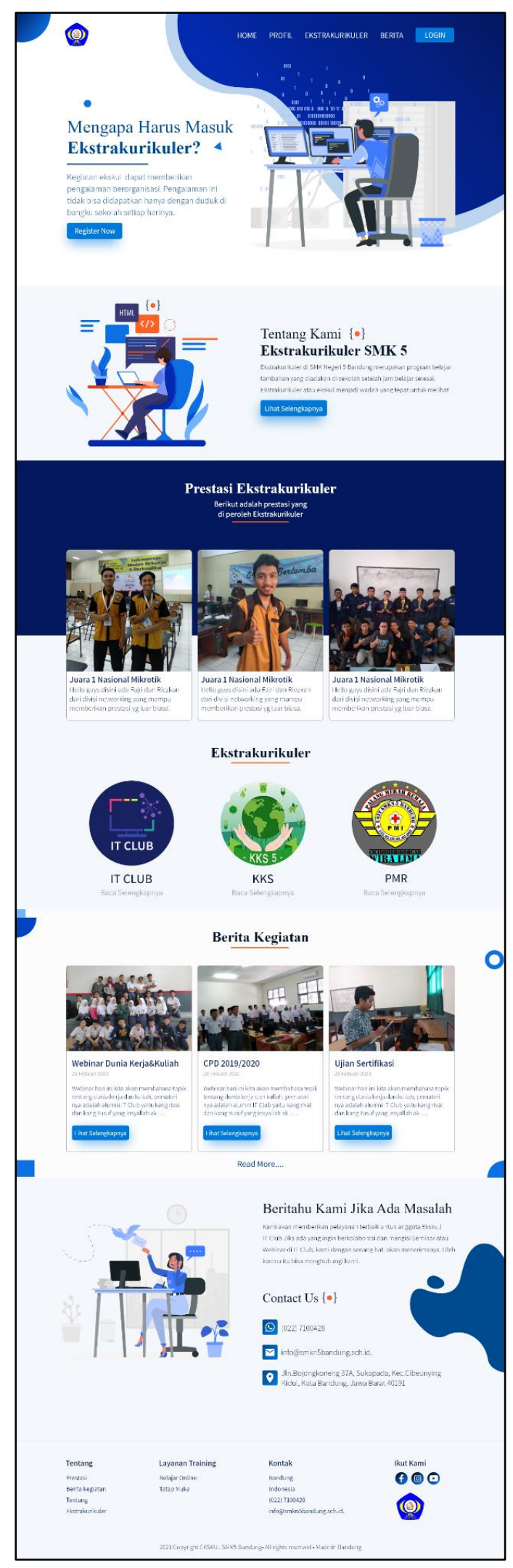

Gambar 11. Tampilan Halaman Home

Gambar 11 menunjukan halaman home yang menampilkan highlight informasi dari beberapa halaman lain. Pada gambar ini terdapat rangkuman informasi seperti tentang, prestasi, ekstrakuriluler, berita kegiatan dan contact us.

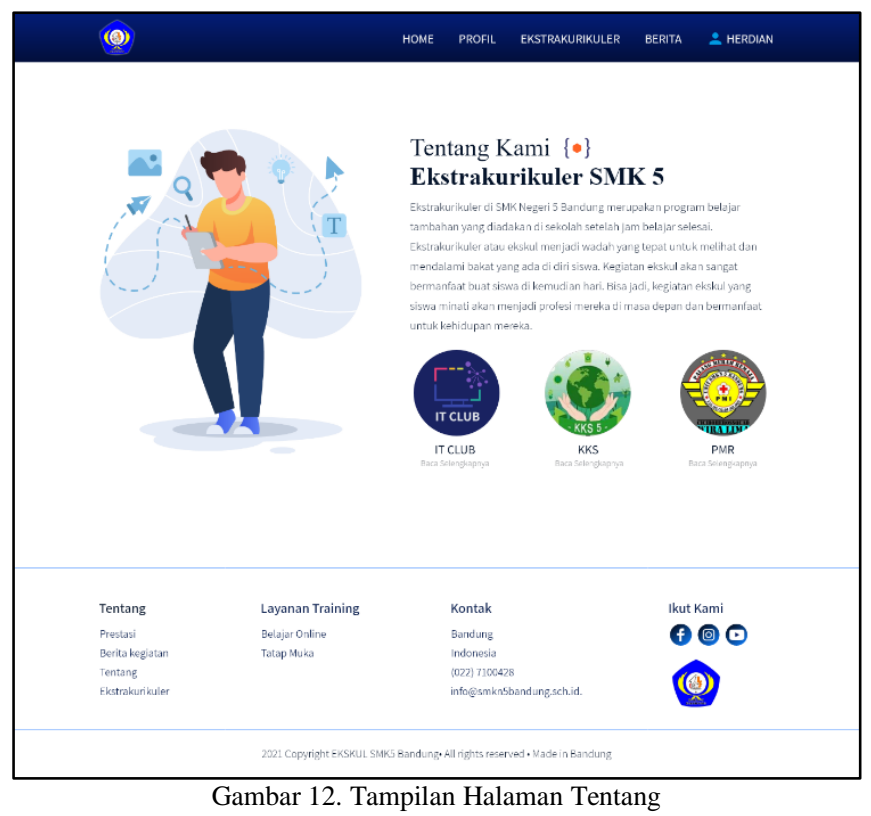

Gambar 12 menunjukan halaman informasi tentang ekstrakurikuler di SMK Negeri 5 Bandung. Pada gambar ini terdapat informasi seperti tentang, ekstrakurikuler dan contact us.

\section{3) Usability Testing}

Usability testing merupakan metode yang digunakan untuk mengukur tingkat efisiensi, kemudahan dalam mempelajari, dan kemampuan untuk berinteraksi tanpa kesulitan. Usability testing memiliki 2 hal penting, yang pertama adalah Ease of learning untuk mengukur kegunaan dengan membandingkan antara waktu yang dibutuhkan untuk mempelajari system yang belum pernah dikenalnya dengan waktu yang dibutuhkan untuk melakukan hal yang sama secara berbeda, yang kedua adalah Ease of use untuk mengukur sejumlah tindakan yang dilakukan dalam menyelesaikan kegiatan [17].

TABEL I. TABEL KUANTITATIF USABILITY TESTING

\begin{tabular}{|l|l|l|}
\hline \multicolumn{1}{|c|}{ Score } & \multicolumn{1}{|c|}{ Kualifikasi } & \multicolumn{1}{c|}{ Hasil } \\
\hline $85-100 \%$ & Sangat Baik (SB) & Berhasil \\
\hline $65-84 \%$ & Baik (B) & Berhasil \\
\hline $55-64 \%$ & Cukup (C) & Tidak Berhasil \\
\hline $0-54 \%$ & Kurang (K) & Tidak Berhasil \\
\hline
\end{tabular}

a. Berhasil Ditemukan

Untuk aspek Kemudahan dipelajari (Learnability) diperoleh angka $100 \%$ dari score 300 dengan score maksilmal 300, efisiensi (Efficiency) diperoleh angka 77,77\% dari score 233,33 dengan score maksilmal 300, kemudahan diingat (Memorability) diperoleh angka 96,83\% dari score 383,33 dengan score maksilmal 400, untuk tingkat kesalahan (Error) diperoleh angka $37,50 \%$ dari score 149,99 dengan score 
maksilmal 400 dan tingkat kepuasan (Satisfaction) diperoleh angka 86,66\% dari score 433,32 dengan score maksilmal 500. Semua persentasi di jumlahkan lalu dibagi dengan jumlah aspek dan mendapatkan hasil nilai rata-rata $79.55 \%$.

\section{b. Tidak Ditemukan}

Untuk aspek kemudahan dipelajari (Learnability) dengan angka kemudahan diingat $0 \%$ dari score 0 dengan score maksilmal 300, efisiensi (Efficiency) diperoleh angka 22,22\% dari score 66,66 dengan score maksilmal 300, (Memorability) diperoleh angka 4,17\% dari score 16,66 dengan score maksilmal 400, untuk tingkat kesalahan (Error) diperoleh angka $62,50 \%$ dari score 249.99 dengan score maksilmal 400 dan tingkat kepuasan (Satisfaction) diperoleh angka 13,33\% dari score 66,66 dengan score maksilmal 500. Semua persentasi di jumlahkan lalu dibagi dengan jumlah aspek dan mendapatkan hasil nilai rata-rata $20.44 \%$.

\section{KESIMPULAN}

Pengelolaan Sistem Informasi Manajemen Ekstrakurikuler berbasis Web pada SMK Negeri 5 Bandung saat ini masih memakai software untuk mengolah data seperti Microsoft dan aplikasi chatting seperti Whatsapp. Dimana hal ini menjadikan proses penginformasian tidak terstruktur bahkan terkadang tidak tersampaikan kepada anggota ekstrakurikuler. Supaya penginformasian dapat lebih terstruktur, efesien dan cepat maka perlu dibuat sebuah Sistem Informasi Manajemen Ekstrakurikuler berbasis Web untuk mewadahi infomarsi yang akan nanti di sampaikan.

Sistem Informasi Manajemen Ekstrakurikuler berbasis Web ini mampu mengolah data anggota, data pembimbing ekstrakurikuler, data alumni, data galeri kegiatan, data nilai, informasi jadwal ekstrakurikuler, prestasi dan mengelola artikel kegiatan yang dilakukan dalam pelaksanaan kegiatan ekstrakurikuler. Dalam system ini Informasi yang ditunjukan selalu diperbaharui dan system ini dapat diakses oleh member, pembimbing ekstrakurikuler, staff ekstrakurikuler, admin dan user (yang sudah terdaftar).

Hasil testing Sistem Informasi Manajemen Ekstrakurikuler berbasis web pada aspek usability testing mendapatkan hasil $79,55 \%$ yang artinya sudah mampu menyelesaikan masalah tidak terstukturnya informasi kepada anggota ekstrakurikuler yang ada di SMK Negeri 5 Bandung. Sehingga dapat disimpulkan, Sistem Informasi Manajemen Ekstrakurikuler berbasis Web sudah memenuhi aspek usability testing dan layak digunakan.

\section{DAFTAR PUSTAKA}

[1] D. Ilham, "Menggagas Pendidikan Nilai Dalam Sistem Pendidikan Nasional," vol. 8, no. 3, pp. 109-122, 2019.

[2] Y. Rahmanto and Y. Fernando, "Rancang Bangun Sistem Informasi Manajemen Kegiatan Ekstrakurikuler Berbasis Web (Studi Kasus : Smk Ma'Arif Kalirejo Lampung Tengah)," J. Tekno Kompak, vol. 13, no. 2, p. 11, 2019, doi: 10.33365/jtk.v13i2.339.

[3] ochamad N. Susila, Badriyah, A. Siregar, and M. Darussalam, "Rancang Bangun Sistem Informasi Website Ekstrakurikuler Smk Yappika Legok Tangerang," vol. 1, pp. 275-284, 2020, [Online]. Available: http://repositorio.unan.edu.ni/2986/1/5624.pdf.

[4] A. Fadillah and A. Ratnasari, "Sistem Informasi Penjualan Dan Manajemen Reimburse Pada Perusahaan Distribusi Berbasis Web (Studi Kasus: Pt. Karyatama Maju Berjaya)," J. Cendikia, vol. XVIII, pp. 298302, 2019.

[5] B. J. Kaleb, V. P. K Lengkong, and R. N. Tareroh, "Penerapan Sistem Informasi Manajemen Dan Pengawasannya Di Kantor Pelayanan Pajak Pratama Manado," J. EMBA J. Ris. Ekon. Manajemen, Bisnis dan Akunt., vol. 7, no. 1, pp. 781-790, 2019, doi: 10.35794/emba.v7i1.22555.

[6] D. Darmawan and A. Ratnasari, "Rancang Bangun Sistem Informasi Manajemen Proyek Berbasis Web Pada Pt Seatech Infosys," J. Sisfokom (Sistem Inf. dan Komputer), vol. 9, no. 3, pp. 365-372, 2020, doi: 10.32736/sisfokom.v9i3.931.

[7] A. Mulyani and R. R. M. Fadilah, "Rancang Bangun Sistem Informasi Ekstrakurikuler di Madrasah Aliyah Negeri 1 Garut Berbasis Web," $J$. Algoritm., vol. 14, no. 2, pp. 177-186, 2017, doi: 10.33364/algoritma/v.14-2.177.

[8] O. Pahlevi, A. Mulyani, and M. Khoir, "Sistem Informasi Inventori Barang Menggunakan Metode Object Oriented Di Pt. Livaza Teknologi Indonesia Jakarta," J. PROSISKO, vol. 5, no. 1, pp. 27-35, 2018, [Online]. Available: https://livaza.com/.

[9] R. Kurniawan and S. Marhamelda, "Sistem Pengolahan Data Peserta Didik Pada Lkp Prima Tama Komputer Dumai Dengan Menggunakan Bahasa Pemrograman Php," I N F O R M a T I K a, vol. 11, no. 1, p. 37, 2019, doi: 10.36723/juri.v11i1.140.

[10] Suendri, "Implementasi Diagram UML (Unified Modelling Language) Pada Perancangan Sistem Informasi Remunerasi Dosen Dengan Database Oracle (Studi Kasus: UIN Sumatera Utara Medan)," J. Ilmu Komput. dan Inform., vol. 3, no. 1, pp. 1-9, 2018, [Online]. Available: http://jurnal.uinsu.ac.id/index.php/algoritma/article/download/3148/187 1.

[11] G. W. Sasmito, "Penerapan Metode Waterfall Pada Desain Sistem Informasi Geografis Industri Kabupaten Tegal," J. Inform. Pengemb. IT, vol. 2, no. 1, pp. 6-12, 2017.

[12] A. R. Putera and M. Ibrahim, "Rancang Bangun Sistem Informasi Peminjaman dan Pengembalian Buku Perpustakaan SMP Negeri 1 Madiun,” DoubleClick J. Comput. Inf. Technol., vol. 1, no. 2, p. 57, 2018, doi: 10.25273/doubleclick.v1i2.2025.

[13] A. Homaidi and A. Lina, "Pengembangan Sistem Informasi Manajemen Berbasis Web dalam Rangka Mendukung Evaluasi Kinerja Akademik dan Dosen di Akademi Manajemen Informatika dan Komputer Ibrahimy,” Appl. Technol. Comput. Sci. J., vol. 2, no. 1, pp. 25-38, 2019, doi: 10.33086/atcsj.v2i1.1125.

[14] A. Mubarak, "Rancang Bangun Aplikasi Web Sekolah Menggunakan Uml (Unified Modeling Language) Dan Bahasa Pemrograman Php (Php Hypertext Preprocessor) Berorientasi Objek," JIKO (Jurnal Inform. dan Komputer), vol. 2, no. 1, pp. 19-25, 2019, doi: 10.33387/jiko.v2i1.1052.

[15] D. Mahdiana, "Pengadaan Barang Dengan Metodologi Berorientasi Obyek : Studi Kasus Pt . Liga Indonesia," J. Telemat., vol. 3, no. 2, pp. 36-43, 2016

[16] A. Hendini, "Pemodelan Uml Sistem Informasi Monitoring Penjualan Dan Stok Barang (Studi Kasus: Distro Zhezha Pontianak)," J. Khatulistiwa Inform., vol. 4, no. 2, pp. 107-116, 2016, doi: 10.2135/cropsci1983.0011183x002300020002x.

[17] D. A. Febrianti, S. H. Wijoyo, and H. M. Az-zahra, "Evaluasi Usability Web UniPin dengan Menggunakan Metode Usability Testing," $J$. Pengemb. Teknol. Inf. dan Ilmu Komput., vol. 3, no. 11, pp. 10547$10555,2019$. 